Rev. Fac. Med. vet. Zootec. Univ. S. Paulo

$12: 40-4,1975$

\title{
CAPACIDADE DO RÚMEN DE OVINOS (OVIS ARIES) DA RAÇA CORRIEDALE §
}

\author{
João Gilberto Lopes PEREIRA * \\ Antonio FERNANDES FILHO * \\ Antonio Alberto D'ERRICO * \\ José PEDUTI NETO *
}

RFMV-A/5

Pereira, J. G. L.; Fernandes Filho, A.; D’Errico, A. A.; Peduti Neto, J.

- Capacidade do rumen de ovinos (Ovis aries) da raca Corriedale.

Rev. Fac. Med. vet. Zootec. Univ. S. Paulo, 12:-40-4, 1975.

Resumo: Foi medida a capacidade do rúmen de 40 carneiros machos, adultos, da raça Corriedale, obtendo-8e a média de 8,750 litros. Os valores máximo e mínimo encontrados correspondem, respectivamente, a 14,700 e 4,950 litros.

Unitermos: Anatomia*; Carneiros*; Rumen*; Aparelho Digestivo.

\section{INTRODUÇÃO E LITERATURA}

0 exame do comprimento do trato intestinal, efetuado nas Disciplinas de Anatomia Descritiva e Topográfica do Departamento de Cirurgia e Obstetrícia da Faculdade de Medicina Veterinária e Zootecnia da Universidade de São Paulo, em carneiros da raça Corriedale (PRADA et al. ${ }^{5}$ - 1971), revelou dados nem sempre concordantes aos fornecidos pelos tratadistas; acrescente-se, ainda, o fato dos AA. clássicos ministrarem, via de regra, ensinamentos genéricos ou imprecisos, especialmente, para a referida espécie pois, muitas vezes, cuidam sob descrição única dos ovinos e caprinos. Agora, recolhemos material de lote homogêneo de animais, para verificar se, também, para a capacidade volumétrica do rúmen encontraríamos valores compatíveis, ou não, aos ex- postos nos livros didáticos, embora, como esclarecemos, não figurem, nestes, especificações quanto ao número, sexo, idade e raça dos exemplares utilizados. Assim, tratando dos pequenos ruminantes, MARTIN ${ }^{4}$ (1904) e SCHUMMER \& NICKEL ${ }^{6}$ (1960) indicam, para a focada medida, limites de 13,0 a 23,0 litros, enquanto COLIN $^{2}$ (1932) registra, como média, 23,40 litros. Por outro lado, LESBRE ${ }^{3}$ (1922), CARADONNA ${ }^{1}$ (1930) e SCHWARZE \& SCHRODER ? (1970) anotam, pela ordem, valores médios de 9,0 litros, 35,0 litros e 12,0 litros, ao estudarem, em particular, o carneiro. Finalizando, em compêndio dedicado à anatomia dessa espécie, encontramos citação de SISSON $^{X}$ (1963), fixando em 8,8 litros a capacidade do rúmen.

§ Trabalho comunicado à XXV Conferência Anual da Sociedade Paulista de Medicina Veterinária - São Pau:, 8 a 14 de setewiro de 1970 e ao $X$ Congresso Brasileiro de $A-9-$ tomia - Florianópolis, 18 a 21 de julho de 1972.

* Professor Assistente Doutor.

Departamento de Cirurgia e Obstetrícia da Faculdade de Medicina Veterinária e Zootecnia da USP. 
PEREIRA, J. G. L.; FERNANDES FILHo, A.; D'ERrico, A. A.; PEDUTI NeTO, J. - Capacidade do rúmen de ovinos (Ovis aries) da raça Corriedale. Rev. Fac. Med. vet. Zootec. Univ. S. Paulo, 12:40-4, 1975.

\section{MATERIAL E MÉTODO}

Para esta pesquisa utilizamos 40 ovinos machos, adultos, da raca Corriedale, obti dos no Instituto Butantā de São Paulo. Com vistas a nosso objetivo, sempre nas cinco primeiras horas subseqüentes ao sacrifício, abríamos a cavidade abdominal, isolávamos o rúmen, separando-o dos demais compartimentos gástricos, limpávamo-lo convenientemente e submergíamo-lo. em recipiente adequado contendo água à temperatura aproximada de $38,5^{\circ} \mathrm{C}$; a seguir, mantendo a víscera imersa, esperávamos seu preenchimento até que as pressōes interna e externa se igualassem. quando, então, vedávamos, com o auxílio de pinças tipo "clamp", os orifícios rumino-reticular e de abertura do esôfago. As manobras seguintes consistiam em retirar o órgão do aludido continente e, comauxílio de vasilhame graduado, medir o volume de líquido contido.

\section{R E S U L T A D O S}

Os valores numéricos patenteados ao avaliarmos a capacidade do rúmen, acham-se discriminados no Quadro $I$, no qual

\section{QUA D R O I}

Capacidade do rúmen (em litros) de ovinos adultos, machos, da raça Corriedale

\begin{tabular}{r|r|r|r}
\hline OBS. & Capacidade (1) & OBS. & Capacidade (1) \\
\hline & & & \\
1 & 7,250 & 21 & 6,750 \\
2 & 8,630 & 22 & 5,100 \\
3 & 7,780 & 23 & 8,750 \\
4 & 9,000 & 24 & 11,300 \\
5 & 10,130 & 25 & 10,500 \\
6 & 7,880 & 26 & 9,650 \\
7 & 6,250 & 27 & 9,850 \\
8 & 12,120 & 28 & 7,950 \\
9 & 8,670 & 29 & 4,950 \\
10 & 9,880 & 30 & 11,000 \\
11 & 7,750 & 31 & 8,000 \\
12 & 5,700 & 32 & 8,050 \\
13 & 6,880 & 33 & 5,550 \\
14 & 6,700 & 34 & 10,800 \\
15 & 11,800 & 35 & 14,700 \\
16 & 7,100 & 36 & 10,850 \\
17 & 8,750 & 37 & 5,700 \\
18 & 8,550 & 38 & 11,000 \\
19 & 9,100 & 39 & 11,100 \\
20 & 9,200 & 40 & 9,200 \\
\hline
\end{tabular}

figuram os registros individuais; a média determinada corresponde a 8,750 litros. Destacamos ainda aqui, os limites máximo e mínimo obtidos, equivalentes, obedecida a seqüência de citação, a 14,700 e 4,950 litros.

\section{COMENTÁRIOS E CONCLUSŌES}

Tal como o sucedido ao ser feita a avaliação do comprimento do trato intestinal em ovinos da raça Corriedale (PRADA et al..$^{5}$ - 1971), também a medida da capacidade volumétrica do rúmen destes animais, apresentou dados nem sempre concordantes aos expostos nos Compêndios de Anatomia. Ainda assim, tal confronto deve ser feito com ressalvas pois, os AA. clássicos eximem-se de informar sobre raça sexo, idade e número dos exemplares observados, quer ao cuidarem especificamente do carneiro (LESBRE ${ }^{3}-1922$; CARA DONNA $^{1-1930 ;}$ SISSON $^{8}-1963$; SCHWARZE \& SCHRODER ${ }^{7}-1970$ ), quer ao examinarem, em conjunto, os pequenos ruminantes (MARTIN ${ }^{4}-1904$; COLIN 2 - 1932; SCHUMMER \& NICKEL $^{6}$ - 1960). Desta forma, notamos que a média de 8,750 litros por nós encontrada, aproxima-se dos valores indicados por LESBRE ${ }^{3}$ (1922), isto é, 9,0 litros e por SISSON 8 (1963), vale dizer, 8,8 litros, afastando-se, mais ou menos, daqueles apontados pelos outros tratadistas. De fato, enquanto MARTIN ${ }^{4}$ (1904)e SCHUMMER \& NICKEL ${ }^{6}$ (1960) estabelecem limites de 13,0 a 23,0 litros, e $\mathrm{CO}$ $\mathrm{LIN}^{2}$ (1932) registra 23,4 litros, a medida máxima em nossos resultados é de 14,700 litros, pouco superior à média consignada por SCHWARZE \& SCHRODER? (1970), de 12,0 litros mas, notadamente inferior à exposta por CARADONNA ${ }^{1}$ (1930), igual a 35,0 litros, encontrando-se, é óbvio, mais distante a anotação mínima que fizemos, ou seja, 4,950 litros.

Contudo, cabe ressaltar, tal discrepância poderia, talvez, correr por conta de eventual disparidade nas características dos espécimes estudados, pois, como ressaltamos acima, os AA. nāo informam sobre raça, sexo, idade e número dos ovinos estudados, como também, muitas vezes, consideram-nos conjuntamente com os caprinos, em capítulo único dedicado aos pequenos ruminantes. 
PEREIRA, J. G. L.; FERNANDES FILHo, A.; D'ERRICo, A. A.; PEDUTI NeTO, J. - Capacidade do rúmen de ovinos (Ovis aries) da raça Corriedale. Rev. Fac. Med. vet. Zootec. Univ. S. Paulo, $12: 40-4,1975$.

RFMV-A/5

Pereira, J. G. L.; Fernandes Filho, A.; D'Errico, A. A.; Peduti Neto, J. - Capacity of the rumen in Corriedale sheeps. Rev. Fac. Med. vet. Zootec. Univ. S. Paulo, 12:40-4, 1975.

SUMMARY: The capacity of the rumen has been mesured in 40 male adult Corriedale sheeps. The mean obtained is 8.750 liters.

UNITERMS: Anatomy*; Sheep*; Rumen*; Digestive system.

\section{REFERENCIAS BIBLIOGRÁFICAS}

1. CaRAdonNA, G. B. - Apparecchio gastro-polmonare. In: ZIMMERL, U.

Trattato di anatomia veterinaria. $\mathrm{Mi}$ lano, Francesco Vallardi, 1930, v. 2, p. 513.

2. COLIN In: ELLENBERGER, W. BAUM, H. - Handbuch der vergleichenden Anatomie der Haustiere. 17 Auf. Berlin, Julius Springer, 1932, p. 442.

3. LESBRE, F. X. - Précis d'anatomie comparée des animaux domestiques. Paris, J. B. Baillière, 1922, v. 1, p. 622 .

4. MARTIN, P. - Lerbuch der Anatomie der Haustiere. Stuttgart, Schickhardt \& Ebner, 1904, v. 2, p. 634.
5. PRADA, I. L. de S. et al. - Comprimento total do intestino em ovinos da raça Corriedale. Rev. Fac. Med. vet., São Paulo, 8(3):651-6, 1971.

6. SCHWARZE, E. \& SCHRODER, L. Kompendium der Veterinar-Anatomie. Jena, Gustav Fischer, 1964, v. 2, p. 72.

7. SISSON In: MAY, N. D. S. - The anatomy of the sheep. 2nd ed. Brisbane, University of Queensland Press, 1964, p. 83 .

Recebido para publicação em 22-5-75

Aprovado para publicação em 17-9-75 